\title{
Um lugar para a América Hispânica na historiografia norte-americana: a fundação da Hispanic American Historical Review e as políticas da história*
}

\author{
A Place for Hispanic America in North American Historiography: the \\ Founding of the Hispanic American Historical Review and the Politics \\ of History
}

\author{
Arthur Lima de Avila \\ arthurlavila@gmail.com \\ Professor Adjunto \\ Universidade Federal do Rio Grande do Sul \\ Rua Santo Antônio, 554/45 - Independência \\ 90220-110 - Porto Alegre - RS \\ Brasil
}

\section{Resumo}

O presente artigo trata da formação de um lugar específico para a veiculação da historiografia norte-americana sobre a América Hispânica, a Hispanic American Historical Review, na década de 1910 nos Estados Unidos. Tal processo, argumenta-se, consolidou a disciplinarização da área naquela conjuntura, assim como em algumas necessidades políticas maiores, como, por exemplo, a legitimação da crescente hegemonia estadunidense ao sul de suas fronteiras - o que a análise de artigos que tratavam da Doutrina Monroe e do suposto antiamericanismo das repúblicas hispano-americanas, veiculados pela revista em seus primeiros anos, procura explicitar. Nesse sentido, o texto busca inferir os modos pelos quais certas historiografias adquirem legitimidade não só a partir de imperativos disciplinares, mas também por conta de necessidades políticas mais amplas.

\section{Palavras-chave}

Historiografia norte-americana; América Hispânica; Hispanic American Historical Review.

\begin{abstract}
This article examines the establishment of a specific publishing place for the American historiography about the Hispanic America, namely the Hispanic American Historical Review, in the 1910s in the USA. The article points out that such process consolidated this field as a discipline in the context of the time and also in terms of a few broader political needs, such as the affirmation of the legitimacy of the increasing hegemony of the USA to the south of its borders - a process that the analysis of selected articles on the Monroe Doctrine and the alleged anti-American mood of the Hispanic American republics, as presented by the journal in its early years, seeks to portray. In this sense, this article analyzes the ways how particular forms of historiography attain legitimacy not only on account of imperatives of their disciplinary fields, but also as a consequence of wider political needs.
\end{abstract}

\section{Keywords}

American historiography; Hispanic America; Hispanic American Historical Review.

Recebido em: 30/5/2014

Aprovado em: 31/8/2014

\footnotetext{
* Trabalho realizado com o auxílio financeiro do CNPq. Todas as traduções são do autor.
} 
Em 1915, um pequeno, mas determinado grupo de historiadores norte-americanos começou a articular a fundação de um novo periódico em seu país. A planejada revista seria voltada à história da "América Hispânica", i.e. as terras ao sul do Rio Grande cujo passado, segundo eles, havia sido por muito tempo negligenciado por seus colegas. Tenazmente, estes intelectuais passaram a angariar apoio disciplinar, financeiro e político para o projeto, com o intuito de rapidamente colocar seu journal em circulação. Entre muitas idas e vindas, sucessos e insucessos, os planos terminaram se concretizando: três anos mais tarde, surgia a Hispanic American Historical Review (HAHR), a primeira revista acadêmica dedicada à história hispano-americana nos Estados Unidos.

Diante deste breve relato, algumas perguntas vêm à tona: por que, naquela conjuntura, a América Hispânica tornou-se um objeto legítimo de estudos para a disciplina histórica? O que permitiu a emergência de um lugar autorizado a tratar de sua história? Quais eram os tipos de história permitidos pelos organizadores e editores da revista - o que podia e o que não podia ser dito nas páginas da revista? Como, enfim, elas se articulavam com a(s) história(s) dos próprios Estados Unidos sancionada(s) pelo establishment profissional?

Ainda que todas estas questões demandem respostas, o foco do artigo é mais modesto e está nas maneiras como, durante o processo que levou à criação da HAHR, seus fundadores buscaram apoio tanto nas autoridades disciplinares, como a American Historical Association (AHA), quanto em uma articulação consciente com as "fontes determináveis do poder político" nos Estados Unidos de então, para citar uma expressão de Edward Said (2010, p. 38). Sob este ângulo, a fundação de um periódico destinado a lidar com a história do "Outro Americano da América", nos termos de João Feres Jr. (2005, p. 82), significava não só o "amadurecimento institucional" de uma determinada área de estudos, como será visto, mas também o estabelecimento de uma competência "científica" para tratar das Américas Central e do Sul derivada de outras necessidades que não somente as da disciplina. Se, por um lado, houve, desde o início do século $X X$, um constante desenvolvimento na historiografia profissional sobre a América Hispânica, por outro, a crescente hegemonia estadunidense na região parecia exigir a criação de um lugar politicamente avalizado para tratar do passado e do presente hispano-americanos. Não quero, entretanto, reduzir a fundação da HAHR a um mero desígnio imperialista, o que seria profundamente simplista, mas sim manter em vista as imbricações mais amplas entre a historiografia acadêmica e o campo político naquela conjuntura, inferindo os modos como a primeira pôde adquirir legitimidade e visibilidade a partir do segundo. ${ }^{1}$

Nesse sentido, tratarei da revista como sendo aquilo que Michel de Certeau (2002, p. 77-78), em suas análises sobre a "operação historiográfica", chamou de "lugar social de produção" do conhecimento histórico. Como colocou o intelectual

\footnotetext{
${ }^{1}$ É preciso destacar a importância que a revista teve na transformação da história da América Hispânica num campo de estudos legítimos dentro da historiografia estadunidense, especialmente o seu papel na divulgação do trabalho de autores do Sul hispânico nos Estados Unidos (como, por exemplo, o brasileiro Gilberto Freyre e o argentino Ricardo Levene, ambos colaboradores da HAHR). Neste caso, a HAHR foi não só uma publicação pioneira, mas continua sendo até os dias de hoje a principal publicação sobre o tema, estando, muitas vezes, no que os anglófonos chamariam de cutting-edge dessa historiografia nos Estados Unidos.
} 
francês, o lugar age como o grande censor, por assim dizer, da historiografia, possibilitando algumas histórias e impossibilitando outras. De modo similar a outros lugares sociais, como as universidades e associações profissionais, a revista sancionava algumas escritas da história da América Hispânica ao concedê-las a devida chancela disciplinar e política. Desse modo, a HAHR se inseria num "labirinto de posições a respeitar e influências a solicitar", para citar Certeau (2002, p. 76), que, por sua vez, não pode ser desvinculado daquela "dependência em relação a um poder estabelecido" que, segundo o mesmo autor (2002, p. 26), é uma característica dos lugares sociais de produção. Não parece ser uma coincidência, assim, que a historiografia sobre a América Hispânica se profissionalize no exato momento em que se pretende consolidar a hegemonia norte-americana na região, na medida em que, segundo Berger (1993, p. 4), o aparecimento da revista não só apontava para a posição complementar que ela ocupou em relação à hegemonia dos Estados Unidos na região, mas também apontava os modos como os discursos profissionais emergentes obtinham sua autoridade de sua proximidade com o governo do país. ${ }^{2}$

$\mathrm{O}$ artigo está dividido em três partes, além desta breve introdução e de algumas considerações finais. Na primeira, faço um curto apanhado da conjuntura disciplinar e historiográfica que possibilitou a criação da revista. A segunda parte, por sua vez, trata do processo mais específico de fundação do periódico, com destaque para a busca de apoio disciplinar e político para a empreitada. Por fim, no terceiro e último ponto, à guisa de exemplo da imbricação do político e do historiográfico em suas páginas, analiso rapidamente dois dos problemas recorrentes na revista em seus primeiros anos: o suposto antiamericanismo ${ }^{3}$ das repúblicas hispano-americanas, entendido como um problema que exigia uma solução, e a Doutrina Monroe, cujas análises visavam a chancelar o direito "histórico" dos Estados Unidos a liderar seus vizinhos meridionais.

Antes de continuar, uma nota sobre terminologia se faz necessária: como o(a) leitor(a) perceberá, em geral, a ideia de "América Hispânica" corresponde à de "América Latina". Optei por usar a primeira por se tratar da linguagem empregada pelas fontes e, como se verá, porque tal uso permite revelar a própria instabilidade dos conceitos sobre a região, conforme utilizados nos Estados Unidos do início do século XX.

\footnotetext{
2 Cabe aqui ressaltar que, em termos políticos, as décadas de 1910 e 1920 consolidaram a transformação dos Estados Unidos em uma potência hemisférica, tanto por sua participação na Primeira Guerra Mundial quanto por um recrudescimento da política do big stick em relação aos países da América Latina, causado, entre outras coisas, pela Revolução Mexicana e o temor norte-americano de que tal processo pudesse ser repetido em outros países. Nesse contexto, como coloca Cristina Pecequilo (2005, p. 89), "a lógica da tutelagem do poder dos Estados Unidos como o 'único' caminho em direção à democracia e ao livre-mercado" converteu-se numa série de intervenções diretas nos assuntos internos das nações meridionais. Mesmo a política externa de Woodrow Wilson, em todo seu idealismo com apelos ao "pan-americanismo" e à "cooperação mútua" entre Norte e Sul, não diminuiu o padrão de intervenção direta e imposição da hegemonia estadunidense na América Latina: "entre 1898 e 1933, os militares norte-americanos intervieram na América Latina em mais ocasiões do que nos cem anos anteriores e mais frequentemente do que fariam nos setenta anos subsequentes" (BREWER 2006 p. 95).

3 "Antiamericanismo" é aqui entendido como o sentimento de oposição exagerada e exacerbada contra os Estados Unidos da América.
} 


\section{De amadores a profissionais: disciplinando a história da América Hispânica}

Quando da publicação do primeiro volume da HAHR, Charles Chapman (1918), um de seus fundadores, afirmou que a criação da revista fora consequência da "pujança" da historiografia sobre a América Hispânica das duas primeiras décadas do século XX. De fato, naquele contexto, a escrita da história sobre aquele "Outro Americano da América" estava deixando de ser a seara de amadores para se transformar em mais um dos campos da disciplina histórica profissional. Isso significava, de acordo com seus próprios praticantes, o abandono dos "exageros de imaginação" e das "especulações românticas" que haviam norteado a produção dos grandes escritores amadores do século XIX, como Francis Parkman, Hubert H. Bancroft e, em especial, William Prescott (EAKIN 1998, p. 540). Esses autores, em que pesem as diferenças entre eles, viam a conquista da América como sendo um grande épico, em que os súditos de Castela haviam submetido um continente inteiro a ferro, fogo e sangue. Apesar de brutal, a vitória dos espanhóis sobre as "raças nativas" fora um triunfo de uma civilização avançada diante de culturas "bárbaras" e "primitivas", ainda que admiráveis em certos aspectos (EAKIN 1998, p. 540-542). Por outro lado, o impacto da conquista havia sido maléfico para ambos os lados: tanto europeus quanto indígenas haviam se "degenerado" em solo americano e, a partir daí, a história local era a da "regressão" da América Hispânica em direção ao "absolutismo", à "superstição", à "autocracia" e ao "fanatismo religioso" (a chamada "lenda negra").

Esses gentlemen historians, chamados de "românticos" por seus sucessores profissionais, contribuiriam para a popularização da história entre o público culto nos Estados Unidos da segunda metade do século XIX, a partir de uma perspectiva que enquadrava a história nacional em um progresso inexorável em direção à democracia. Este avanço, contudo, dava-se a partir de uma luta de civilizações que era inerente ao próprio processo histórico: de um lado, estavam as civilizações que, como os Estados Unidos protestantes e democráticos, estavam destinadas a ser as vencedoras da contenda; de outro, estavam aquelas cuja decadência era inevitável diante do curso da história, como os países "absolutistas" e "católicos", dos quais, talvez, a Espanha e suas antigas colônias fossem os maiores exemplos (BENDER 2011, p. 374).

Com a profissionalização da historiografia sobre a América Hispânica, ocorreu, segundo Benjamin Keen e Charles Gibson (1957, p. 858), a sua transformação em uma "entidade autóctone", a disciplinarização de seu "método" e a educação dos outros historiadores sobre a sua importância. Houve, poirtanto, a sua "adequação", por assim dizer, às normas que passaram a reger o conhecimento histórico nos Estados Unidos e consistiam, dentre outras coisas, na sacralização do ideal objetivista como sendo o credo dos historiadores: a história da América Hispânica deveria ser contada de modo "desinteressado", "desapaixonado" e "científico", para citar três palavras em voga no discurso profissional de então. ${ }^{4}$ Isso levou os historiadores da América Hispânica à

\footnotetext{
${ }^{4}$ A melhor análise sobre a profissionalização da história nos Estados Unidos continua sendo a obra de Peter
} 
adoção de uma postura que, se não se furtava a julgamentos similares àqueles emitidos pelos "românticos" do século anterior, abjurava seus "devaneios filosóficos" e "assomos ficcionais" em prol de versões "realistas" do passado hispano-americano: os historiadores deveriam narrar os fatos o mais "fielmente possível", sem especulações desnecessárias ou estetizações exageradas. ${ }^{5}$

Ainda assim, em seu contexto maior, a profissionalização da história nos Estados Unidos servia a um propósito público, e político, maior (de resto, não muito diferente do que acontecia na Europa ocidental): formar uma consciência cívica na população e, sobretudo, servir como fonte de instrução para os estadistas do porvir. ${ }^{6}$ Nas palavras de um de seus maiores entusiastas naquele momento, $\mathrm{J}$. Franklin Jameson, a história deveria servir à boa formação dos cidadãos e líderes do Estado e da nação (BENDER 2011, p. 378). Uma "boa" historiografia deveria ser tanto objetiva e rigorosa em suas adjudicações quanto comprometida com os problemas e preocupações de seu tempo. Não haveria aqui, assim, uma necessária contradição entre uma historiografia que se postulava "científica" e "objetiva" e seu compromisso com seu tempo presente, como colocaram Thomas Bender (2011, p. 383) e Ian Tyrrell (1999, p. 1120-1121): mesmo os mais empiristas dos historiadores estadunidenses acreditavam que, quanto mais verdadeira a história, melhor ela poderia servir a este "interesse público".

No caso específico da historiografia sobre a América Hispânica, isso significava uma atenção redobrada às relações entre os Estados Unidos e seus vizinhos meridionais e o diagnóstico dos supostos "vícios de origem" destes últimos. Aqui, os intelectuais dividiam-se em dois grandes grupos: de um lado estavam os "liberais internacionalistas" que advogavam a necessidade de cooperação mútua entre os países americanos, com a consequente conformação de um "pan-americanismo" sob a liderança norte-americana; de outro, estavam os chamados "anglo-saxonistas", que enfatizavam a "hierarquia racial" entre os Estados Unidos anglo-saxões e protestantes e a América Hispânica mestiça e católica, e que compreendiam os problemas desta última através das lentes de um racismo cientifico amplamente aceito na academia norte-americana de então (BERGER 1993, p. 4). ${ }^{7}$

\footnotetext{
Novick (1988). Cabe aqui lembrar a colocação de Hayden White de que a disciplinarização da história envolvia, antes de mais nada, a disciplinarização da imaginação dos historiadores profissionais. Ver WHITE 1994, p. 157-172.

${ }^{5}$ Exemplos destas histórias profissionais "desinteressadas" podem ser encontrados nos trabalhos de autores como Edward Gaylord Bourne e Bernard Moses, que consideravam a conquista espanhola como o avanço da civilização em um continente "bárbaro", mesmo que, no longo prazo, o catolicismo e a mestiçagem racial houvessem transformado a América Hispânica numa região "atrasada" e "reacionária", especialmente se comparada à república do Norte (BERGER 1993, p. 2-3; TYRRELL 1999, p. 1026-1027).

6 Como analisa Chris Lorenz (2010, p. 74): "the methodological identification of academic history with 'objectivity' was implicitly connected to the political theory of the 'supra-partisan' nation-state". Desta forma, a história era também vista como uma disciplina voltada à formação de quadros para a burocracia estatal e para o campo político.

7 Nas primeiras décadas do século XX, segundo Bender (2011, p. 381), boa parte dos historiadores aceitava, explícita ou implicitamente, este anglo-saxonismo e suas afirmações sobre a superioridade dos anglo-saxões e do protestantismo. Exemplo disso é a ampla aceitação das teses racistas de William Dunning sobre a história do Sul dos Estados Unidos e a "perversidade" da Reconstrução e da ideia de igualdade racial - que visava, em última instância, a neutralizar a luta política dos afro-americanos e a naturalizar o que era então chamado de "governo do homem branco". O racismo científico só entraria em declínio a partir da década de 1930, mas continuaria perdurando em alguns bolsões disciplinares, mesmo que de forma tímida, até os anos 1960 . Ver NOVICK 1988, p. 80-82.
} 
Entre os críticos desses "anglo-saxonistas", contudo, prevaleceu a visão inaugurada por Herbert Bolton, e depois promovida por vários de seus alunos, de que o anglo-saxonismo era uma visão "paroquial" da história dos Estados Unidos, já que não só ocultava uma parte fundamental dessa mesma história, como também não contribuía para uma aproximação efetiva entre as duas Américas. ${ }^{8}$ Nesse sentido, a "escola" inaugurada por Bolton, cuja influência nos campos de história da América Hispânica e de história do Oeste seria enorme, colocava-se firmemente ao lado dos "pan-americanistas" - o que significava que, para o historiador e seus orientandos, os problemas de "desenvolvimento" da América Hispânica eram de origem cultural, mais do que qualquer outra coisa. Uma cooperação entre as duas Américas, portanto, poderia ajudar na resolução dessas dificuldades (TRUETT 2005, p. 231-235).

No que tange à institucionalização acadêmica da historiografia sobre a América Hispânica, Bolton foi um de seus agentes mais importante, se não o mais. Ele diligentemente perambulou por arquivos mexicanos catalogando e transcrevendo documentos sobre a história daquele país e do Sudoeste estadunidense; orientou mais de cem teses de doutorado, a grande maioria sobre as borderlands ou temas hispano-americanos; organizou a Bancroft Library em Berkeley, composta não só da antiga biblioteca pessoal de Hubert $\mathrm{H}$. Bancroft, mas de diversas outras fontes seminais sobre a América Hispânica; e, finalmente, transformou o Departamento de História em Berkeley no principal lugar de produção dedicado à história hispano-americana nos Estados Unidos. Além disso, dentro do sistema "clientelista" que Ian Tyrrell (1986, p. 54-60) identificou como sendo a principal característica das universidades estadunidenses de então, Bolton indicou e obteve a nomeação de diversos de seus antigos alunos para postos importantes em várias instituições do país - não coincidentemente, dois dos fundadores da HAHR, Charles Chapman e William S. Robertson, eram ex-orientandos de Bolton. Portanto, a atuação de Bolton foi essencial para a legitimação da história da América Hispânica nas universidades norteamericanas e a profissionalização desta não pode ser separada de sua trajetória pessoal (TRUETT 2005, p. 213-247).

Por outro lado, o crescimento e a institucionalização dessa historiografia estavam, como coloca Mark Berger (1993, p. 3), vinculados não somente à dinâmica interna da profissão nos Estados Unidos nas duas primeiras décadas do século $X X$, com o crescimento do número de departamentos de história pelo país, de estudantes de pós-graduação, de revistas publicadas e da

\footnotetext{
8 Professor das universidades do Texas e em Berkeley, nesta última por trinta e três anos, Bolton teve um papel fundamental não só na reescrita da história do Sudoeste dos Estados Unidos, mas também na institucionalização da história da América Hispânica. No primeiro caso, o historiador considerava os espanhóis como agentes da civilização nas borderlands, lutando contra o meio ambiente hostil e as tribos "selvagens" da região. Nesse sentido, por exemplo, aquela instituição tão condenada pelos historiadores "anglo-saxonistas", a missão, não era um sinal de fanatismo religioso; muito pelo contrário, era um instrumento civilizacional que atestava a grandeza do projeto imperial espanhol na América do Norte. Inspirado na frontier thesis de Frederick Jackson Turner, com quem havia estudado na Universidade de Wisconsin, Bolton via a história do império espanhol no Novo Mundo como sendo um épico sobre a conquista de um continente inóspito e bravio pelas mãos de um valente povo de pioneiros. Ver TRUETT 2005, p. 223-227.
} 
diversificação dos temas e objetos, mas também ao aumento da presença norte-americana ao sul. Sob este ângulo, a criação da HAHR parecia também dizer respeito ao estabelecimento de um lócus para a enunciação de discursos profissionais e "científicos" sobre a região. Neste caso, tal lócus era essencial para a conformação desse objeto: na medida em que a historiografia possuía um caráter pretensamente "científico" e "objetivo", as suas representações do passado hispano-americano, sempre relacionado com sua contraparte norte-americana, possuíam uma autoridade magisterial, para usar o termo de Certeau (2002, p. 66), com ampla ressonância social. Isso significa que as produções historiográficas sobre a América Hispânica não só adquiriam um status de "verdadeiras" por serem escritas por historiadores, mas também podiam fornecer legitimidade "científica" às pretensões de outros campos, como o político. Assim, não surpreende o interesse de diversos homens de Estado norte-americanos na fundação e na consolidação da HAHR, como veremos no próximo ponto.

\section{De historiadores e presidentes: a construção de um lugar}

Segundo Charles Chapman (1918, p. 8), então professor em Berkeley, o que levou à criação da revista foi justamente essa necessidade de organizar um campo aparentemente caótico e em franca expansão. Isto pareceu ficar claro para Chapman, segundo seu próprio testemunho, durante um painel realizado no encontro da American Historical Association (AHA) de 1915, em que a pujança da nova historiografia chamou-Ihe atenção. ${ }^{9}$ J. Franklin Jameson (1918, p. 6), então editor da AHR e um dos nomes mais poderosos da profissão, ecoou sentimentos semelhantes quando da publicação do primeiro número da HAHR:

[...] de todos os departamentos de história que a América possivelmente poderia premiar com um periódico histórico especial, não há nenhum outro que tenha feito maiores avanços em anos recentes, nenhum que esteja agora em curso de rápido desenvolvimento, como o que a HISPANIC AMERICAN HISTORICAL REVIEW tomou como seu território. ${ }^{10}$

Para Chapman e para mais alguns de seus colegas, portanto, ficava clara a demanda de um periódico capaz de organizar e veicular essa crescente produção historiográfica.

No ano seguinte, Chapman e William S. Robertson, professor da Universidade de Illinois, viajaram à Argentina para tomar parte nas atividades do Congresso Americano de História e Bibliografia, realizado em Buenos Aires em honra do

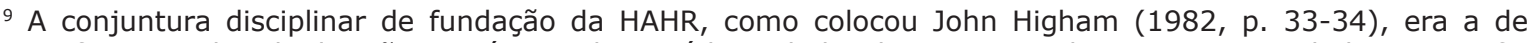
uma fenomenal multiplicação no número de periódicos dedicados aos mais diversos campos da historiografia profissional. Isso atestaria, segundo ele, a expansão da disciplina em direção a searas pouco ou nunca antes visitadas e, por consequência, a sua diversificação nas primeiras décadas do século XX. Fez-se necessário, assim, o surgimento de novas revistas que pudessem dar conta de todos os objetos e temas à disposição dos historiadores norte-americanos. Dentre os periódicos importantes fundados nesse período, podem ser mencionados, dentre outros, o Agricultural History, o New England Quarterly, Journal of Economic and Business History e o Journal of Modern History.

${ }^{10}$ No original: "[...] of all the departments of history that America might conceivably furnish with a special historical periodical, there is none that has made greater advances in recent years, none that is now in a course of more rapid development, than that which the HISPANIC AMERICAN HISTORICAL REVIEW has taken for its province".
} 
centésimo aniversário da independência da república platina. Durante o evento, os historiadores norte-americanos não só foram convencidos da obrigação de se ampliarem os intercâmbios intelectuais entre o Norte e o Sul, como também tomaram a decisão final de persuadir seus colegas estadunidenses a apoiar a criação de um novo periódico histórico nos Estados Unidos (CHAPMAN 1916, p. 83-86; 1918, p. 9).

Para além desse imperativo disciplinar, contudo, havia outro, igualmente importante e de particular urgência. De acordo com Chapman (1918, p. 8-9), a aproximação cada vez maior entre os Estados Unidos e seus vizinhos meridionais exigia um maior conhecimento destes por aquele, para que suas políticas para a região pudessem ser bem conduzidas. ${ }^{11}$ Dito de outro modo, era necessário criar um lugar não só para organizar tal historiografia, mas para direcioná-la, autorizá-la e legitimá-la diante da profissão e do grande público, a partir de uma demanda que era também política.

Já em 1916, começaram a se estabelecer negociações com a American Historical Association (AHA) e com outras instituições para a criação da nova revista. Isso era necessário, principalmente, para trazer apoio profissional para o projeto, na medida em que a AHA era, então, o órgão que dava chancela aos periódicos de história nos Estados Unidos. Mesmo que ela não possuísse o poder legal de barrar esses empreendimentos, uma má vontade ou negativa explícita do presidente e dos conselheiros desta instituição em apoiar a criação da HAHR poderia significar o seu fracasso. Isso se refletiu na troca de correspondência entre Chapman e a direção da $A H A$, em que deixava explícita sua intenção e a de seus colegas de fundar uma revista dedicada única e exclusivamente aos temas "ibero-americanos" (CHAPMAN 1918, p. 10-11). A ênfase no "exclusivamente" não era gratuita: durante as primeiras décadas do século $X X$, o comitê editorial do veículo oficial da AHA, The American Historical Review (AHR), liderado pelo já mencionado J. Franklin Jameson, era extremamente cuidadoso com revistas que, porventura, pudessem se sobrepor aos seus interesses. Garantir que a HAHR não fosse competir academicamente com a AHR era, assim, um modo de angariar o apoio da AHA à sua criação.

Para além de seus contatos continuados com a AHA, Chapman e Robertson também tentaram convencer seus pares por meios mais diretos. A maneira encontrada por ambos para medir a aceitação do projeto por seus colegas foi por meio de um questionário enviado pelo correio a setenta e dois nomes importantes para a profissão (os nomes, contudo, permaneceram confidenciais). O sucesso de tal empreitada, a julgar pelo relato de Chapman (1918, p. 11), foi razoável. Dos setenta e dois historiadores contatados, sessenta responderam à inquirição, com quarenta e seis declarando-se amplamente favoráveis a criação da Review e enfatizando seu possível papel

\footnotetext{
${ }_{11}$ Charles Chapman mantinha uma relação próxima com o Departamento de Estado norte-americano, como coloca Berger (1995, p. 12), ainda que nunca tenha trabalhado diretamente para tal instituição. No entanto, um dos livros de Chapman, "A History of the Cuban Republic", publicado em 1927, foi financiado pelo Instituto Carnegie, sob os auspícios do então embaixador norte-americano em Cuba, Louis Perez, Jr.
} 
na criação de um "bom" relacionamento com a América Hispânica, diplomática e intelectualmente falando. ${ }^{12}$

Amparado por tal recepção, Chapman se reuniu com um seleto grupo de historiadores, cientistas sociais e alguns empresários no encontro da AHA de 1916, para discutir os rumos da futura publicação. Ao fim do congraçamento, ficou decidido, no que tangia aos objetivos e temas principais da revista, provisoriamente chamada de Ibero-American Historical Review, que:

Deve-se prestar atenção à história social, econômica e política (incluindo a diplomática) tanto quanto à mera narração externa de eventos, e alguns materiais contemporâneos podem ser utilizados de tempos em tempos; a América Hispânica deve ser o campo principal, mas deve ser interpretada de modo a incluir todo o Caribe e as partes dos Estados Unidos que pertenceram um dia à Espanha e ao México antes de sua anexação por este país; artigos sobre as Filipinas, contanto que tratem de temas espanhóis, podem ser aceitos também (CHAPMAN 1918, p. 13). ${ }^{13}$

Este outline do programa historiográfico da revista é bastante revelador. Para além de um projeto historiográfico que se imaginava amplo, a definição de "América Hispânica" era suficientemente abrangente para incluir o Caribe inglês e francês, o Sudoeste norte-americano e, em menor escala, as Filipinas. Isto demonstra justamente o escopo temático pretendido pelos fundadores e sua busca pelo estabelecimento de um lugar de produção que pudesse dar conta do maior número de objetos e temas possíveis. Por outro lado, isso revela a própria instabilidade do conceito de "América Hispânica" naquela conjuntura, o que poderia levar a uma multiplicidade de representações sobre a região. Como veremos, contudo, tal situação seria logo resolvida com o recurso a uma definição muito mais limitadora da "América Hispânica", baseada menos em questões espaciais do que em questões identitárias e raciais.

Como já foi dito, em paralelo à busca por legitimação disciplinar para a revista, Chapman e Robertson procuraram ancorar-se no poder político. Para tanto, escreveram cartas a diversas figuras importantes, incluindo o então secretário de Estado, Robert Lansing, um dos artífices da política "pan-americanista" do governo estadunidense; o secretário do Tesouro, William McAdoo; e o próprio presidente da República, Woodrow Wilson - ele mesmo, aliás, um historiador. A recepção dos três foi extremamente calorosa. Lansing louvou o projeto, afirmando sua importância para a aproximação entre as Américas:

Acredito que uma revista de história latino-americana seria de grande benefício, tanto para os estudiosos deste país quanto para os da América

\footnotetext{
12 Dos doze que se opuseram, apenas três expressaram sua posição, afirmando que ainda não haveria material suficiente para a criação de uma revista do tipo nos Estados Unidos, o que demonstra que a visão sobre a "pujança" da historiografia sobre a América Hispânica não era unânime entre os historiadores norteamericanos (CHAPMAN 1918, p. 11).

${ }^{13}$ No original: "Attention should be paid to social, economic, and political (including diplomatic) history as well as to the mere external narration of events, and some contemporary materials might be used from time to time; Hispanic America should be the principal field, but that ought to be interpreted as including the entire Caribbean area and those parts of the United States formerly under Spain and Mexico for the periods prior to their annexation to this country; articles on the Philippines, in so far as they related to things Spanish, might also be accepted".
} 
Latina. Ela também serviria ao propósito pelo qual todos nós temos lutado, tanto no passado quanto especialmente no presente, isto é, a fundação de uma relação mais próxima entre todas as Américas (LANSING apud CHAPMAN 1918, p. 23). ${ }^{14}$

McAdoo, por sua vez, afirmou que tal empreendimento contribuiria substancialmente para a melhora das relações da América Hispânica com os Estados Unidos, já que criaria um veículo comum para a discussão de problemas históricos que, segundo ele, interessariam a todos os povos das Américas (McADOO apud CHAPMAN 1918, p. 23).

Wilson expressou seu apoio à revista em termos bastante parecidos. Numa carta que mereceu destaque no primeiro volume da HAHR, ele escreveu:

Fico sabendo com grande interesse dos planos de uma Ibero-American Historical Review e peço que expresse a todos os interessados minha mais sincera aprovação do projeto. Ele é deveras interessante e pode levar a resultados muito importantes tanto para o conhecimento quanto para o aumento do sentimento cordial através das Américas (WILSON 1918, p. 1). ${ }^{15}$

O suporte dado por esses nomes demonstra, assim, a proximidade existente entre o estudo do passado e a formulação de políticas no presente, mesmo que de forma tênue. Ainda que a HAHR não tenha sido pensada unicamente como um instrumento para a legitimação da hegemonia estadunidense na América ao sul de suas fronteiras, era possível, como indicam os documentos acima, que o periódico ajudasse neste processo.

Ademais, como o próprio Chapman (1918, p. 17) deixou claro, o aval dado por alguns dos mais importantes nomes da República era um instrumento de encorajamento para o apoio de outros setores da sociedade estadunidense ao periódico. Neste caso, o poder político funcionava como um avalista tão importante quanto a anuência acadêmica à fundação da HAHR.

\section{De nomes, histórias e doutrinas: por que contar a história da América Hispânica?}

Como o(a) leitor(a) deve ter percebido, Lansing, McAdoo e Wilson usaram termos diferentes para se referir à América ao sul de suas fronteiras. Isso se devia, segundo Feres Jr. (2005, p. 72-74), à ausência de um significante estável para aquele "Outro Americano da América". Mesmo que se reconhecesse a diferença fundamental entre os Estados Unidos e aquele Outro coletivo meridional, ainda não existia um conceito unânime para defini-lo. Ainda que a ideia de América Latina circulasse nas Américas do Sul e Central, segundo Walter Mignolo (2005,

\footnotetext{
${ }_{14}$ No original: "I believe that a Journal of Latin-American History would be of great benefit, both to the scholars of this country and to those of Latin America. It would also serve the purpose for which all of us have been striving both in the past, and, particularly, in the present, namely the foundation of a closer relationship between all of the Americas".

15 No original: "I learn with a great deal of interest of the plans for an Ibero-American Historical Review and beg that you will express to all those interested my very sincere approval of the project. It is a most interesting one and ought to lead to very important results both for scholarship and for the increase of cordial feeling throughout the Americas".
} 
p. 82-83), desde meados do século XIX, nos Estados Unidos ela só seria incorporada à linguagem cotidiana em fins da mesma centúria e só substituiria completamente os outros termos depois da Segunda Guerra Mundial.

No caso da revista, o problema do nome a ser utilizado apareceu durante a captação de recursos. Em busca de dinheiro, Chapman e Robertson obtiveram uma doação de três mil dólares de um milionário espanhol residente nos Estados Unidos, J. C. Cebrián. Como coloca Feres Jr. (2005 p. 81-82), o patrocínio de Cebrián geraria uma intensa discussão sobre o nome da publicação. 0 espanhol estava incomodado com o nome Ibero-American Historical Review, sugerido pelos idealizadores, já que, segundo ele, o termo "ibérico" poderia ser igualmente utilizado em referência à França. $O$ segundo nome pensado, Latin American Historical Review, era também problemático aos olhos de Cebrián, já que dizia respeito, além de Portugal e Espanha, à Itália e, novamente, à França. Como as Américas Central e do Sul haviam sido colonizadas quase que exclusivamente pelos dois primeiros, ${ }^{16}$ o nome mais adequado seria Hispanic American Historical Review, já que o adjetivo "hispânico" era o "único adequado cientificamente" às nações portuguesa e espanhola. Para Cebrián, o termo "Latin America" não seria "científico", além de "ambíguo" e "enganador". "Hispanic America", por seu turno, seria inapelavelmente "científico", "claro", "verdadeiro" e "justo". Diante de tais argumentos, e necessitando do dinheiro, os editores terminaram aceitando o nome proposto pelo milionário espanhol (CHAPMAN 1918, p. 16-18). ${ }^{17}$

Com a anuência de seus pares e com o devido financiamento, os editores conseguiram publicar o primeiro número da HAHR em fevereiro de 1918. Sem exceções, os artigos desse primeiro número eram dedicados à história diplomática e política da região. Nas edições seguintes, e a despeito da vontade anteriormente expressada por Chapman, de privilegiar outros âmbitos, a história política se manteve dominante. De acordo com Mark Berger (1995, p. 31), isso seria reflexo de uma suposta baixa qualidade do conhecimento sobre a América Hispânica então produzido nos Estados Unidos. No entanto, tal historiografia deve ser avaliada diante de sua conjuntura disciplinar mais ampla. Ainda que a história social e a história econômica já tivessem um prestígio muito grande dentro das universidades do país, a importância institucional da história política e diplomática ainda era inegável, como demonstra Thomas Bender (2011, p. 377381). Além disso, como o campo historiográfico profissional dedicado à América Hispânica ainda era muito incipiente, boa parte do material ainda era produzido por amadores, diplomatas e cientistas políticos - o que ajuda a explicar a opção

\footnotetext{
${ }^{16}$ Cebrián não se esqueceu do Haiti. No entanto, segundo ele, "os poucos milhares de negros e negróides que corrompem a língua francesa" naquele país dificilmente poderiam ser considerados latinos (CHAPMAN 1918, p. 17). Se por um lado a aceitação dos argumentos racistas de Cébrian é sintomática de uma conjuntura na qual o racismo científico ainda possuía credibilidade, como colocou Feres Jr. (2005, p. 83), por outro é preciso aventar se tal aceitação por parte de Chapman, reconhecido como um historiador não-racista numa resenha publicada no Journal of Negro History (1934, p. 198-199), não teria sido menos fruto de convicções pessoais do que da necessidade de angariar fundos para o projeto.

17 De acordo com Peter Novick (1988, p. 65), doadores poderosos poderiam ter uma influência generalizada na definição dos limites do discurso acadêmico naquele período, principalmente nos conselhos de administração das universidades norte-americanas de então, públicas ou privadas. Aparentemente, em vista do exemplo acima mencionado, o mesmo podia ser verdadeiro para outros órgãos acadêmicos, como as revistas, por exemplo.
} 
por um recorte político para a análise do passado da região. ${ }^{18} \mathrm{~A}$ partir disto, pode-se entender melhor o privilégio obtido pela história política e diplomática da América Hispânica nas páginas da HAHR em seus primeiros anos. ${ }^{19}$

No caso dos artigos voltados à história política hispano-americana dos séculos XIX e XX, os temas da Doutrina Monroe e do suposto "antiamericanismo" das repúblicas meridionais mereceram amplo destaque nos primeiros anos da revista. ${ }^{20}$ É a partir destes textos que podemos inferir a dimensão política da historiografia veiculada na HAHR e seu papel na construção de narrativas que legitimavam a hegemonia norte-americana na América Hispânica.

Em fevereiro de 1920, a HAHR publicou um artigo em que Edward Perry (1920, p. 17-40) analisava as origens da propaganda antiamericana nos países hispano-americanos, justamente para, segundo ele, encontrar uma maneira de neutralizá-la. Em primeiro lugar, Perry retomava o tradicional tema da Lenda Negra, a ideia de que a Espanha era uma nação dominada pela ignorância e pelo fanatismo religioso, cronicamente incapaz de se modernizar, para traçar uma breve história política de uma América Hispânica, segundo ele, sufocada por trezentos anos de estagnação e autocracia. Esse despotismo, personificado na própria cultura da região, estava em evidente contraste com o espírito democrático do Norte anglo-saxão. Para Perry (1920, p. 17-18), esse era um antagonismo "natural" encarnado na própria História Universal:

Conservadores, reacionários e mercenários persistem em tentar impedir, mesmo que eles saibam que não podem parar o avanço da democracia por muito tempo. Esses oponentes demonstram não compreender que este avanço é um passo inevitável na evolução da humanidade, nem que aqueles que não podem ou não conseguem acompanhar esta marcha devem ser esmagados (PERRY 1920, p. 17). ${ }^{21}$

O cenário para sua análise estava dado, portanto. De um lado, a força inexorável da democracia e de seus aliados. De outro, seus inimigos. Partindo

\footnotetext{
$\overline{18}$ A fragilidade institucional da história da América Latina era clara nesses anos. Apesar do surgimento da HAHR em 1918, a primeira associação profissional de estudos latino-americanos, a Conferência de História da América Latina, só surgiria no final da década de 1920 (BERGER 1993, p. 6-7).

19 De acordo com uma pesquisa realizada por Lesley Simpson e publicada na comemoração do trigésimo aniversário da revista, $54 \%$ dos artigos publicados na HAHR em suas primeiras décadas de existência estavam devotados a temas referentes aos séculos XIX e XX, com o século XVI em terceiro lugar. Nos três casos, contudo, os recortes eram eminentemente políticos. De acordo com Simpson (1948, p. 189-190) isso representaria uma "miopia temporal" dos colaboradores da revista, que "acreditavam" que os eventos mais recentes eram mais importantes do que os mais afastados temporalmente. Tal coisa era condenável aos olhos do autor, na medida em que, de acordo com ele, a história da América Latina só poderia ser entendida pelo estudo dos "padrões de longa duração" e não somente pela análise da história política e diplomática da região (SIMPSON 1949, p. 191-192). Desse modo, na postura de Simpson já fica nítida a reorientação da historiografia norte-americana ocorrida a partir de meados da década de 1930, quando a história social e a história econômica tornam-se institucionalmente mais importantes do que a história política e a história intelectual. Sobre esse processo, ver os seminais trabalhos de Peter Novick (1988) e John Higham (1982).

20 Dos cinquenta e oito artigos publicados na revista em seus primeiros quatro anos, trinta foram dedicados a temas diversos dos séculos XIX e XX. Destes, sete tinham por objeto a Doutrina Monroe e/ou o alegado antiamericanismo das repúblicas hispano-americanas - o que totaliza quase um terço dos artigos de "história recente" veiculados pela revista naquele contexto - um número nada desprezível. Ver http://www.jstor.org/ action/showPublication?journalCode=hispamerhistrevi. Acesso em: 23 maio 2014).

${ }^{21}$ No original: "Conservatives, reactionaries and mercenaries persist in striving to check, even if they know they cannot long stop democracy's advance. These opponents do not show that they comprehend that this advance is an inevitable step in the evolution of mankind, nor that all who will not or cannot keep pace with that march must be trampled into dust".
} 
dessa premissa, Perry (1920, p. 28) argumentava que as "raças" que haviam perecido diante dos pioneers haviam morrido justamente por sua oposição a um processo histórico que era tanto inescapável quanto implacável:

Nenhuma raça morreu por causa da vinda dos pioneiros aos Estados Unidos; as raças que aqui morreram causaram sua própria extinção através de ataques repetidos e selvagens contra pessoas cuja meta era conquistar os obstáculos da terra bravia e converter seus materiais naturais para o conforto e o avanço da humanidade. Aqueles pioneiros combateram o indígena bárbaro assim como o mexicano de sangue hispânico [...]..$^{22}$

Sob esse ângulo, o destino da América Hispânica era profundamente ambíguo: se seu próprio caráter a forçava a uma existência condenada a sofrer com tiranetes e autocratas diversos, a intervenção norte-americana na região podia salvá-la de tal sina. Para tanto, era necessário analisar e neutralizar a propaganda antiamericana na região a partir de um esforço maciço do governo e dos intelectuais estadunidenses em convencer as "classes pensantes" da América Hispânica sobre a "verdadeira" natureza deste processo histórico, demonstrando os fatos "reais" com toda a "honestidade" possível e desmistificando as críticas "infundadas" que os Estados Unidos recebiam de seus vizinhos meridionais. Com a conquista dos corações e mentes hispano-americanos, Perry (1920, p. 39-40) considerava que, "naturalmente", eles aceitariam o Norte como seu guia moral e econômico.

Seguindo uma linha similar de raciocínio, William Dunn (1920, p. 177183), em artigo publicado na edição seguinte, explicitava a sua apreensão em relação ao surgimento de um "sentimento antiamericano" nas repúblicas hispânicas da região. Segundo ele, toda uma sorte de políticos e intelectuais estava explorando ou estimulando desavenças entre a "mais antiga república das Américas" e seus vizinhos meridionais. De acordo com ele, isso seria extremamente contraproducente para a consolidação de um "pan-americanismo saudável e responsável". Dunn (1920, p. 178) certamente considerava o "passado imperialista" dos Estados Unidos como um entrave ao desenvolvimento de um relacionamento amigável entre as Américas, mas, na sua visão, o cerne do problema estava no "antagonismo natural entre dois povos de duas culturas diferentes", repetindo, assim, o topos do conflito inevitável entre "hispânicos" e "anglo-saxões". O autor julgava que o "pan-hispanismo" defendido por certos intelectuais latino-americanos era uma decorrência "natural" dessa oposição entre a América do Norte anglo-saxônica e a América Hispânica. A saída para esse impasse era justamente uma maior intervenção dos Estados Unidos na esfera cultural desta última, com o intuito de equilibrar e reverter essa suposta propaganda negativa (DUNN 1920, p. 178-179). Concluía ele:

Os Estados Unidos estão em julgamento diante destas repúblicas. Elas erguem suas mãos para nos receber como amigos e sócios, não em

\footnotetext{
22 No original: "No race died because of the coming of the pioneers of the United States; the races that died here brought their own extinction by repeated and savage raids on people whose aim was to conquer the obstacles of the wilderness, and to convert its natural materials to the comfort and advancement of humanity. Those pioneers fought the barbarous Indians as the Mexican of Hispanic blood [...]".
} 
uma aliança desigual, mas em uma aliança de justiça imparcial para todos. Elas precisam de nosso capital e esperam que as auxiliemos no desenvolvimento de seus recursos. Nunca antes os Estados Unidos precisaram tanto de uma política hispano-americana consistente quanto no presente (DUNN 1920, p. 183).23

A "necessidade de desenvolvimento" inferida por Dunn aponta para um dos elementos constitutivos dessas representações do passado (e do presente) da América Hispânica, isto é, a retórica da modernidade que Ihes dá sustentação. Aqui, há uma leve mudança de percepção em relação ao artigo de Perry. As terras ao sul dos Estados Unidos não seriam necessariamente "bárbaras", mas somente "atrasadas" em relação ao Norte. Nesse caso, seria necessário seu "desenvolvimento" por meio da providencial ajuda do capital setentrional, fosse ele humano ou monetário. Como coloca Mignolo (2005, p. 36-38), a retórica da modernidade oculta, através de um salvacionismo "universalista", justamente a lógica colonial que lhe é subjacente. Pode-se inferir, destarte, que a "política hispano-americana" consistente almejada por Dunn era nada menos do que a salvaguarda da hegemonia norte-americana na região, diante da competição com outras potências imperiais. E uma das formas históricas de justificar a "política consistente" aventada por Dunn era justamente a Doutrina Monroe e seu papel nas relações entre as repúblicas do Sul e o país do Norte. ${ }^{24}$ Ela acabou sendo objeto de três artigos publicados na revista entre 1920 e 1921.

Em fevereiro de 1920, a Review publicou um artigo de William S. Robertson sobre as "apreciações hispano-americanas" do famoso credo do presidente James Monroe (1817-1825). Segundo o historiador, ao contrário do que era amplamente imaginado, a aplicação de tal doutrina não foi necessariamente atacada com hostilidade pelos "hispano-americanos". Por meio da análise de fontes governamentais, especialmente documentos diplomáticos, Robertson considerou que, quando não utilizada para fins unicamente imperiais, a ideia de que os Estados Unidos deveriam tutelar e proteger seus "irmãos" do sul não fora rechaçada pelos habitantes das Américas Central e do Sul. Segundo o autor, a Doutrina Monroe não seria outra coisa além do "legítimo" reconhecimento de que Washington deveria "auxiliar" os hispano-americanos no seu desenvolvimento e na condução de seus negócios externos, tendo em vista a fragilidade institucional e internacional de tais países. Para Robertson, este reconhecimento deveria levar a um "pan-americanismo" liderado pelos Estados Unidos e sustentado pela Doutrina Monroe. Novamente, portanto, a retórica da modernidade dá suporte a

\footnotetext{
23 No original: "The United States is on trial before these republics. They stand with outstretched hand to receive us as friends and associates, not in any inequitable alliance, but in one of impartial justice to all. They need our capital and they are expecting us to aid them in developing their resources. Never before has the United States been in greater need of a consistent Hispanic American policy than at the present day".

24 A "Doutrina Monroe" foi anunciada pelo presidente James Monroe (1817-1825) no contexto do processo de independência dos países da América Latina. Temendo uma recolonização da região por parte dos antigos impérios europeus, inspirada pela derrota de Napoleão Bonaparte e a consolidação da Santa Aliança, os Estados Unidos declararam seu franco apoio aos novos países e sua oposição a qualquer reimposição da autoridade colonial nas áreas recém-autonômas. Com isso, Monroe lançou ao mundo sua famosa consigna "América para os americanos", afirmando, desse modo, que a América Latina estava sob a esfera de influência norte-americana e que Estados Unidos, se necessário, recorreriam à força para assim mantê-la.
} 
uma interpretação do passado (e do presente) da América Hispânica que enfatiza sua necessidade de "orientação" e "proteção" pela potência setentrional.

Nos números seguintes, Julius Klein (1921, p. 248-255) e Samuel Inman (1921, p. 635-676) continuaram com a avaliação da doutrina. De acordo com Klein, a Primeira Guerra Mundial havia provocado um realinhamento das relações entre os países latino-americanos, levando-os a uma maior integração, especialmente no âmbito econômico (KLEIN 1921, p. 251). Tal situação levou os Estados Unidos a renunciar aos aspectos mais belicosos e intervencionistas da Doutrina Monroe, amplamente criticados por Klein (1921, p. 252) como sendo contraproducentes aos interesses de longo prazo dos norte-americanos. O reforço dos laços econômicos entre as Américas seria, assim, um dos pilares de sustentação de uma política pan-americana maior, sempre comandada pelos Estados Unidos. O outro seria a defesa das nações americanas, também liderada pelos estadunidenses, contra os "males do bolchevismo" e do "comunismo internacional" (KLEIN 1921, p. 254). Essas mudanças de conjuntura assegurariam a hegemonia dos Estados Unidos na região, sem a necessidade de intervenções militares, principalmente porque os países do Sul necessitavam da liderança do país do norte e, por isso, estariam "dispostos" a cooperar.

Tal diagnóstico era compartilhado por Samuel Inman (1921, p. 635-676). Assim como Klein, Inman repudiava as aplicações violentas da Doutrina Monroe como sendo antagônicas à sua intenção original, isto é, a preservação da forma de governo republicana nas Américas contra as ameaças do Velho Mundo. Recuperando o contexto histórico da anunciação da Doutrina, logo após as independências das antigas colônias espanholas, Inman narra a história de uma América Hispânica presa entre duas possibilidades: o reconhecimento de seu pertencimento à esfera de influência dos Estados Unidos, o que garantiria sua liberdade, ou a recolonização, forçada e brutal, por parte dos impérios europeus. Por isso, diante dessa ameaça, a ajuda estadunidense seria:

[...] parcialmente egoísta e parcialmente altruísta, como todo princípio natural deve ser. Deve parecer bastante natural supor que os Estados Unidos, tendo sido uma nação fraca em seus primeiros dias, estavam particularmente interessados em se proteger e em avançar a grande ideia de democracia da qual foram pioneiros. O governo democrático que eles, egoísta e altruisticamente desejavam ver crescer - egoísta no sentido de que o desenvolvimento de tal governo no continente americano tenderia a fortalecer sua própria vida, e altruísta porque se desejava encorajar e ajudar outras pequenas nações a realizar esse mesmo ideal (INMAN 1921 , p. 646). ${ }^{25}$

Repetindo o que já fora dito várias vezes antes, o problema das repúblicas latino-americanas, aos olhos de Inman (1921, p. 637-639), não era de origem

\footnotetext{
${ }^{25}$ No original: "[...] the doctrine is partly selfish and partly altruistic, as every natural principle should be. It seems very natural to suppose that the United States, being a weak nation in the early days, was particularly interested in protecting itself and also in advancing the great idea of democracy of which it was the pathfinder. Democratic government it selfishly and unselfishly desired to see grow - selfishly in that the development of such government on the American continent would tend to strengthen its own life, unselfishly in that it wished to encourage and assist other small nations to realize the same ideal".
} 
racial ou institucional, mas sim de "maturidade política". Sem essa maturação, as repúblicas hispânicas precisariam do auxílio de seus irmãos mais velhos do Norte na luta contra os pérfidos interesses imperiais dos europeus (e da Inglaterra, em especial). Recuperando a "lei histórica" que sanciona a influência do "mais forte" sobre o "mais fraco", Inman (1921, p. 656) afirmava, portanto, ser "natural" a preponderância norte-americana na região:

Os Estados Unidos se desenvolveram cem vezes mais rapidamente do que qualquer outro país na América, e como consequência natural desse desenvolvimento, eles necessariamente assumiram a liderança das nações americanas. Esse é mais ou menos o enredo de toda a história. Se a América Hispânica gosta ou não disso, não há como prevenir que a nação mais avançada e poderosa do grupo exerça sua maior influência. ${ }^{26}$

Sob esse ponto de vista, a Doutrina Monroe era a expressão política da tendência histórica à preponderância estadunidense. ${ }^{27}$ Neste caso, existiria uma inevitabilidade quase trágica nas ações dos Estados Unidos na América Hispânica:

Talvez nós pudéssemos tê-lo feito de outra maneira; melhores maneiras poderiam ter sido encontradas. Ainda assim, o fardo nos foi dado e não poderíamos escapar dele, então tomamos a liderança, assim como outras grandes nações fizeram em partes do mundo onde sua influência era dominante (INMAN 1921, p. 656)..$^{28}$

Essa "inevitabilidade" trágica, contudo, também impunha sua cota de sacrifícios aos norte-americanos: considerando a noblesse oblige de seu país, Inman (1921, p. 676), em sua conclusão, afirmava que, se necessário, os Estados Unidos derramariam até sua última gota de sangue em defesa da democracia e em proteção aos seus "irmãos" meridionais.

\section{Considerações finais}

À guisa de conclusão, pode-se inferir que a fundação da HAHR respondeu, assim, não só a necessidades disciplinares, mas também a demandas políticas: os dois âmbitos, nesse caso, não podem ser facilmente separáveis, já que a historiografia da América Hispânica parecia retirar parte de sua legitimidade justamente de sua dependência de um poder estabelecido, como atesta a busca de apoio dos criadores da revista junto a importantes nomes políticos daquele contexto, incluindo o Presidente da República. As fontes determináveis do poder

\footnotetext{
${ }^{26}$ No original: "The United States has developed a hundred times more rapidly than any other country in America, and as a natural outgrowth of that development it has necessarily assumed the headship of the American nations. It is more or less the story of all history. Whether we like it or whether Hispanic America likes it, there is no way of preventing the most advanced and most powerful nation in the group from exercising the greatest influence".

${ }^{27}$ Evidentemente, nesta leitura existe uma relação entre a Doutrina Monroe e a formulação posterior conhecida como "Destino Manifesto", criada na década de 1840, que imputava que a posse do continente que se estendia do Atlântico ao Pacífico havia sido concedida aos Estados Unidos pela Divina Providência. Na segunda metade do século XIX, a ideia do Manifest Destiny foi secularizada e a naturalização das conquistas e da hegemonia norte-americana era elaborada a partir de seu governo democrático, economia capitalista e espírito pioneiro. Sobre isto, ver a clássica obra de Richard Slotkin (1992).

${ }^{28}$ No original: "Perhaps we did not have to do it in quite the way we did; better ways could have been found. Nevertheless the burden was laid upon us and we could not get away from it, so we took the lead just as other great nations have done in other parts of the world where their influence was dominant".
} 
político, nesse caso, foram fundamentais para o sucesso da revista, que não pode ser compreendido somente como um resultado "natural" do desenvolvimento da disciplina, mas como consequência da imbricação entre o lugar social de produção do conhecimento histórico e suas influências labirínticas. Se não se pode resumir a criação da revista a um mero ato imperial, não se pode, igualmente, ignorar as ressonâncias do projeto norte-americano de hegemonia na América Hispânica em suas páginas. Como, então, poderíamos compreender as análises sobre a Doutrina Monroe expostas acima e a busca pelas raízes do, supostamente rampante, "antiamericanismo" hispano-americano?

Igualmente, se, parafraseando Berger (1995), o diagnóstico e a avaliação dos problemas regionais eram necessários para "civilizar o Sul", a retórica de modernidade, entendida acima nos termos de Walter Mignolo (2005), era um dos topoi para se compreender a história do "Outro Americano da América". Ambos, as necessidades de "modernização" e de "civilização", eram entendidos como fundamentais para salvar a região de seu secular "atraso", conformando-a, assim, ao rumo "natural" do processo histórico, encarnado nos Estados Unidos da América. Isto, evidentemente, poderia ser alcançado pela "aceitação", por parte dos países meridionais, da preponderância da República do norte, refletida, para citar novamente Inman, na sua "disposição" em estender a mão e o capital aos seus vizinhos mais pobres. Nesse caso, parece-me, havia uma clara finalidade política em algumas das narrativas expostas nas páginas da HAHR em seus primeiros anos: legitimar, justificar e naturalizar a hegemonia estadunidense em termos "científicos", i.e. históricos.

\section{Referências bibliográficas}

BENDER, Thomas. Writing American History, 1789-1945. In: MACINTYRE, Stuart; MAIGUASCHA, Juan; PÓK, Attila (org.). The Oxford History of Historical Writing: volume 4: 1800-1945. Oxford: Oxford University Press, 2011, p. 369-389.

BERGER, Mark. Civilizing the South: The US rise to hegemony in the Americas and the roots of "Latin American Studies", 1898-1945. Bulletin of Latin American Research, v. 12, n. 1, p. 1-48, 1998.

. Under Northern Eyes: Latin American Studies and U.S. hegemony in the Americas, 1898-1990. Bloomington: Indiana University Press, 1995.

. Civilising the South: The US Rise to Hegemony in the Americas and the Roots of 'Latin American Studies' 1898-1945. Bulletin of Latin American Research, v. 12, n. 1, p. 1-48, 1993.

BREWER, Stuar. Borders and Bridges: A history of U.S.-Latin American relations. Wesport: Praeger, 2006.

CERTEAU, Michel de. A escrita da história. Rio de Janeiro: Forense Universitária, 2002.

CHAPMAN, Charles. The American Congress of Bibliography and History at 
Buenos Aires. The American Historical Review, v. 22, n. 1, p. 83-86, 1916.

The Founding of the Review. The Hispanic-American Historical Review, v. 1, n. 1, p. 8-23, 1918.

DUNN, W. E. The Post-War attitude of Hispanic America towards the United States. The Hispanic-American Historical Review, v. 3, n. 2, p. 177$183,1920$.

EAKIN, Marshall. Latin American History in the United States: From gentlemen scholars to academic specialists. The History Teacher, v. 31, n. 4, p. 539-561, 1998.

FERES Jr., João. A história do conceito de "Latin America" nos Estados Unidos. Bauru: Edusc, 2005.

HIGHAM, John. History: Professional scholarship in America. Baltimore: The Johns Hopkins University Press, 1982.

INMAN, Samuel Guy. The Monroe Doctine and Hispanic America. The HispanicAmerican Historical Review, v. 4, n. 2, p. 248-255, 1921.

JAMESON, J. Franklin. A new American Historical Journal. The HispanicAmerican Historical Review, v. 1, n. 1, p. 2-7, 1918.

KEEN, Benjamin; GIBSON, Charles. Trends of United States studies in Latin American History. The American Historical Review, v. 62, n. 4, p. 855$877,1957$.

KLEIN, Julius. The Monroe Doctrine as regional understanding. The HispanicAmerican Historical Review, v. 4, n. 2, p. 248-255, 1921.

LORENZ, Chris. Unstuck in time. Or: the sudden presence of the past. In: TILMANS, Karin; VREE, Frank van; WINTER, Jay (org.). Performing the Past: Memory, history, and identity in Modern Europe. Amsterdam: Amsterdam University Press, 2010, p. 67-102.

MIGNOLO, Walter. La idea de America Latina: La herida colonial y la opción decolonial. Barcelona: Gedisa, 2005.

NOVICK, Peter: That Noble Dream: The "Objectivity Question" and the American historical profession. Cambridge: Cambridge University Press, 1988.

PECEQUILO, Cristina Soreanu. A política externa dos Estados Unidos. Porto Alegre: UFRGS, 2006.

PERRY, Edward. Anti-American propaganda in Hispanic-America. The HispanicAmerican Historical Review, v. 3, n. 1, p. 17-40, 1920.

ROBERTSON, William Spence. Hispanic-American appreciations of the Monroe Doctrine. The Hispanic-American Historical Review, v. 3, n. 1, p. 1-16, 1920. 
SAID, Edward. Orientalismo: O Oriente como invenção do Ocidente. São Paulo: Cia. das Letras, 2010.

SIMPSON, Lesley Byrd. Thirty years of the Hispanic American Historical Review. The Hispanic American Historical Review, v. 29, n. 2, p. 188-204, 1949.

SLOTKIN, Richard. The Gunfighter Nation: The myth of the frontier in $20^{\text {th }}$ century America. Norman: University of Oklahoma Press, 1992.

TRUETT, Samuel. Epic of Greater America: Herbert Eugene Bolton's quest for a transnational American History. In: SCHMIDT-NOWARA, Christopher; NIETO-PHILLIPS, John M. (org.). Interpreting Spanish Colonialism: Empires, nations and legends. Albuquerque: University of New Mexico Press, 2005. p. 213-247.

TYRRELL, Ian. The Absent Marx: Class analysis and liberal history in $20^{\text {th }}$ century America. Westport: Greenwood Press, 1986. . Making Nations / Making States: American historians in the context of empire. The Journal of American History, v. 86, n. 3, p. 1015-1044, 1999.

WHITE, Hayden. Trópicos do Discurso: ensaios sobre a crítica da cultura. São Paulo: Edusp, 1994.

WILSON, Woodrow. A letter from President Wilson. The Hispanic-American Historical Review, v. 1, n. 1, p. 1, 1918. 